\title{
A critical review of pro-cognitive drug targets in psychosis: convergence on myelination and inflammation
}

\section{Rune A. Kroken ${ }^{1}$, Else-Marie Løberg ${ }^{1,2}$, Tore Drønen ${ }^{1}$, Renate Grüner ${ }^{3,4}$, Kenneth HugdahI 1,2,3,5, Kristiina Kompus $^{2}$, Silje Skrede ${ }^{5,6,7}$ and Erik Johnsen ${ }^{1,8}$}

' Division of Psychiatry, Haukeland University Hospital, Bergen, Norway

${ }^{2}$ Department of Biological and Medical Psychology, University of Bergen, Bergen, Norway

${ }^{3}$ Department of Radiology, Haukeland University Hospital, Bergen, Norway

${ }^{4}$ Department of Physics and Technology, University of Bergen, Bergen, Norway

${ }^{5}$ NORMENT Center of Excellence, University of Bergen, Bergen, Norway

${ }^{6}$ Dr. Einar Martens' Research Group for Biological Psychiatry, Centre for Medical Genetics and Molecular Medicine, Haukeland University Hospital, Bergen, Norway

${ }^{7}$ Department of Clinical Science, K.G. Jebsen Centre for Psychosis Research, University of Bergen, Bergen, Norway

${ }^{8}$ Department of Clinical Medicine, University of Bergen, Bergen, Norway

Edited by:

André Schmidt, University of Basel,

Switzerland

Reviewed by:

Joshua T. Kantrowitz, Columbia University, USA

Wen-Jun Gao, Drexel University

College of Medicine, USA

Paolo Fusar-Poli, King's College

London, UK

*Correspondence:

Rune A. Kroken, Division of

Psychiatry, Haukeland University

Hospital, PB 1400, N-5021 Bergen,

Norway

e-mail: rune.kroken@helse-bergen.no
Antipsychotic drugs have thus far focused on dopaminergic antagonism at the D2 receptors, as counteracting the hyperdopaminergia in nigrostriatal and mesolimbic projections has been considered mandatory for the antipsychotic action of the drugs. Current drugs effectively target the positive symptoms of psychosis such as hallucinations and delusions in the majority of patients, whereas effect sizes are smaller for negative symptoms and cognitive dysfunctions. With the understanding that neurocognitive dysfunction associated with schizophrenia have a greater impact on functional outcome than the positive symptoms, the focus in pharmacotherapy for schizophrenia has shifted to the potential effect of future drugs on cognitive enhancement. A major obstacle is, however, that the biological underpinnings of cognitive dysfunction remain largely unknown. With the availability of increasingly sophisticated techniques in molecular biology and brain imaging, this situation is about to change with major advances being made in identifying the neuronal substrates underlying schizophrenia, and putative pro-cognitive drug targets may be revealed. In relation to cognitive effects, this review focuses on evidence from basic neuroscience and clinical studies, taking two separate perspectives. One perspective is the identification of previously under-recognized treatment targets for existing antipsychotic drugs, including myelination and mediators of inflammation. A second perspective is the development of new drugs or novel treatment targets for well-known drugs, which act on recently discovered treatment targets for cognitive enhancement, and which may complement the existing drugs. This might pave the way for personalized treatment regimens for patients with schizophrenia aimed at improved functional outcome. The review also aims at identifying major current constraints for pro-cognitive drug development for patients with schizophrenia.

Keywords: schizophrenia, cognition, glutamate, myelin, inflammation, immunology, connectivity, neuroimaging

\section{INTRODUCTION}

Schizophrenia is a severe mental disorder with typical onset in the late teens or early adulthood and a chronically relapsing remitting course in the majority of cases (1). Schizophrenia remains a leading cause of years lived with disability (2), and active psychosis has been ranked among the most disabling disorders by severity in the general population (3).

The clinical picture of schizophrenia is heterogeneous, but in the vast majority of patients, cognitive dysfunctions are present with adverse impact on daily functioning (1). Antipsychotic drugs have for six decades been a cornerstone in the treatment of the disorder but a fundamental limitation is their small effect sizes in the cognitive symptom domain (4) as the drugs are primarily effective against the positive symptoms of psychosis including hallucinations and delusions (4). Since the serendipitous discovery of chlorpromazine's antipsychotic properties, dopaminergic antagonism has served as a template for all subsequent antipsychotics through counteracting subcortical hyperdopaminergia (5). The drugs following chlorpromazine are usually classified as typical or first generation antipsychotics (FGAs), whereas clozapine much later became the prototype for the atypical or secondgeneration antipsychotic (SGA) drugs that were developed in the 1990s onward $(4,6)$. Only modest differences in antipsychotic efficacy have been found among FGAs and SGAs (7), but the SGAs seem to display a broader therapeutic repertoire including also pro-cognitive properties, although of a small magnitude (8). Pharmacologically, the FGAs have strong affinities for the dopamine type 2 (D2) receptor, whereas the SGAs are characterized by a 
more pronounced 5-HT2A antagonism than FGAs, and a lower potency for the D2 receptor $(9,10)$. The narrow focus on the dopaminergic system and striatal hyperdopaminergia in particular has most likely contributed to the limited evolvement of more effective drug treatment options as it has become increasingly clear that dopaminergic disturbances account for only parts of the clinical picture (particularly for positive symptoms) (1113 ), and hyperdopaminergia is not present in all schizophrenia patients (14).

Recognizing the large impact that the schizophrenia associated cognitive dysfunctions have on functional outcome $(15,16)$, the efforts to improve the pharmacological treatment have moved toward cognitive enhancement, and pro-cognitive effects have been proposed as primary targets in future drug studies $(17,18)$. A major obstacle restricting hypothesis-driven pro-cognitive drug development has been the lacking knowledge of the structural and functional brain alterations underlying cognitive dysfunction in patients with schizophrenia $(19,20)$. Major scientific advances in unveiling the neurobiology of schizophrenia have emerged in recent years, however. The knowledge of transmitter dysfunctions especially is widened (21), accompanied by evidence of disturbances of myelination and inflammation/immunology in the pathophysiology of schizophrenia $(22,23)$. Thus, going beyond the neurotransmitter disturbances associated with schizophrenia, the present work reviews the latest evidence on myelin alterations, and the involvement of neuroinflammation/immunology in schizophrenia, with putative relevance for pro-cognitive drug effects in schizophrenia and related psychotic disorders. Moreover, these areas seem at least partly inter-related and the review aims at integrating the evidence from key publications in a joint model. Increased insight into the relevant functional and structural alterations might pave the way for more efficacious, targeted, and personalized pro-cognitive drug treatment opportunities aimed at improving real-world functioning. The review focuses on both previously unknown treatment targets for existing antipsychotic drugs, and potentially novel pro-cognitive drugs addressing extra-dopaminergic treatment targets, and gives an update also commenting on current constraints of pro-cognitive drug development for patients with schizophrenia.

\section{COGNITIVE DYSFUNCTION IN PATIENTS WITH SCHIZOPHRENIA}

Cognitive function may be understood in terms of inter-related complex neural networks, influenced by different neurotransmitters, cytokines, and other substances including brain-derived neurotropic factor (BDNF) acting as neuromodulators (24).

Cognitive deficits are viewed as core characteristics of schizophrenia, with clinically significant cognitive impairments observed in a large majority of patients, and most patients experience lower cognitive functioning than would be expected from parental levels of education $(16,25)$. Cognitive deficits are seen before the development of psychosis (25-28), and cognitive decline and intellectual stagnation have been suggested to constitute a risk phenotype for developing schizophrenia (25). Furthermore, cognitive deficits are relatively stable after psychotic breakthrough and still present when the symptoms of psychosis have been treated $(29,30)$. A general cognitive dysfunction across cognitive domains is present, with additional selective deficits in working memory, executive function, attention, verbal fluency, episodic memory, and processing speed $(15,31)$. The effect size of the cognitive dysfunction compared to healthy subjects is close to $1.0(32,33)$, and in several neurocognitive dimensions the impairment is between 1 and 2 SDs, indicating a clinically significant loss of function $(25,34-37)$. Cognitive functioning has greater impact than positive psychotic symptoms in determining the patient's real-world functional outcome $(15,38-41)$, and relationships between more specific cognitive domains and functional domains have also been reported $(38,40,42)$. Thus, cognitive impairment has been put forward as the main target for novel treatment interventions in schizophrenia (25).

A significant challenge has been to develop clinical meaningful measures of cognitive dysfunction for pro-cognitive drug advancement. A major contribution to establish a standardized and manageable test battery for measuring cognition in schizophrenia has been the development of the Measurement and Treatment Research to Improve Cognition in Schizophrenia (MATRICS) Consensus Cognitive Battery (MCCB) (43). The MCCB composite score has been suggested as the best outcome measure based on findings of low practice effects, high test-retest reliability, and good external validity (44), while a recent factor analysis identified a three factor model of processing speed, attention/working memory, and learning as the best representations of data in this particular study (45).

\section{DOES ABNORMAL MYELINATION CAUSE COGNITIVE DYSFUNCTIONS IN PATIENTS WITH SCHIZOPHRENIA?}

Myelin, the main constituent of white matter, is essential for controlling and regulating conduction velocities along axons and thus the synchronicity of brain signals across different brain regions, and for controlling synapse plasticity (46). Decreased myelin integrity might accordingly alter normal signal transduction. In the following, we will focus on one major line of recent achievements in schizophrenia research, namely the rapidly expanding knowledge of abnormal central nervous myelination in patients with schizophrenia and the possibilities to prevent or repair myelin pathology. White matter brain alterations and functional connectivity problems that have been linked to cognitive dysfunctions in schizophrenia will be briefly described, followed by in-depth descriptions of new findings of myelin alterations linked to cognition. Again, a major problem is to identify manageable tests/measures of myelinization and myelin integrity that can be used in drug discovery programs in a reliable way. Finally, we will discuss candidate drug treatments counteracting deficits of myelinization in patients with schizophrenia

\section{WHITE MATTER CHANGES AND COGNITION}

Several distinct alterations in gray and white matter are well established for schizophrenia patients as a group (47). Reviews of white matter tract pathology in patients with schizophrenia [mostly studies based on voxel-based morphometry (VBM) and diffusion tensor imaging (DTI)] have identified widespread and, in many studies, progressive changes (47). A meta-analysis of 15 DTI studies by Ellison-Wright and Bullmore (48) identified reductions (in all studies) of left frontal deep white matter and 
left temporal white matter. Thus, the authors suggested that two different networks may be affected; one connecting the frontal lobe with thalamus and cingulate gyrus, the other connecting the temporal lobe with, e.g., insula, amygdala, hippocampus, and the frontal lobe. A review by Walterfang et al. (49) of white matter pathology in patients with schizophrenia identified changes in the left uncinate fasciculi as the most replicated finding, furthermore that deficits of information processing was associated with volume reductions in the uncinate and inferior longitudinal fasciculi, anterior internal capsule, and corpus callosum (49). White matter pathology related to cognition has also been found in first-episode patients with psychosis. For example, Rigucci and colleagues (50) reported a relationship between speed of processing and visual memory and white matter fractional anisotropy (FA) in fronto-temporal tracts. Focusing on intra-cortical white matter, several clusters of superficial white matter (SWM) composed of U-shaped fibers connecting neighboring gyri together with intra-cortical axons and fibers from deep matter pathways displayed reduced FA in a study comparing patients with schizophrenia to healthy controls. The correlations between SWMFA and cognition displayed in healthy controls were missing in patients (51).

\section{FUNCTIONAL CONNECTIVITY STUDIES}

Recently, also related to myelination, the search for brain alterations underlying the psychopathology of schizophrenia has refocused to examine neuronal dysconnectivity, i.e., abnormal communication between local and distributed neuronal circuits or disrupted integration of brain activation (52-54). Fornito et al. (53) reviewed data on brain connectivity, and concluded that schizophrenia is associated with: (1) a widespread and possibly context-independent connectivity deficits, (2) additional transient states of hyper- and/or hypo-connectivity related to specific tasks.

Disturbed connectivity within the frontal lobes has been found to be related to working memory and to executive functioning $(52,54)$. This includes abnormal connectivity in fronto-parietal, fronto-cerebellar, and fronto-hippocampal networks (52). Verbal processing deficits have been shown to be related to circuits in the language areas of the brain, particularly to fronto-temporal dysfunction $(52,54)$. Indeed, theories have been developed concentrating on the effect of reduced executive cognitive control over the language processing in the temporal lobes as central to the development of the symptoms of psychosis, for instance auditory verbal hallucination (55).

Of future interest may be the influence of antipsychotic drugs on the dynamic interaction between large-scale cortical networks related to resting and effort-mode states (56). Using fMRI, Hugdahl et al. (57) found overlapping activation in a large-scale network to occur with a range of different cognitive tasks implicating the prefrontal cortex [see also Ref. (58)] suggesting that effective cognitive processing would require down-regulation of the resting-state network in situations with increasing demands for the up-regulation of the effort-mode network, and that cognitive impairment in schizophrenia may result from failure of network up- and down-regulation dynamics. Thus, based on brain imaging results, therapeutic agents inducing stabilization and, ideally, normalization of large-scale cortical network dynamics could possibly have pro-cognitive effects. However, thus far no drug has been reported to enhance connectivity (52).

The major question related to the structural basis of functional dysconnectivity was addressed in the review by Fornito et al. (53). The authors concluded with major overlaps between functional and structural findings, but also differences, which could at least partly be caused by intrinsic problems of the methods of structural measurements (see Measuring Myelination).

\section{MEASURING MYELINATION}

Several methodological issues need consideration regarding the use of imaging techniques for myelin assessments. The DTI signal may reveal changes in white matter integrity but has limitations in identifying the exact nature of these changes, as the FA reflects different processes like demyelination, axonal swelling, or atrophy, and is sensitive to confounding effects of fiber crossings (59). In a recent review by Du and Öngür (60), two novel MR-based approaches - diffusion tensor spectroscopy (DTS) and magnetization transfer ratio (MTR) - were reviewed as measures of axonal diameter (DTS) and myelin volume (MTR). Combining MTR with DTI, Palaniyappan et al. (61) recently showed that the degree of FA reduction in areas with decreased myelin volume predicted impaired processing speed, leading the authors to suggest that combined DTI/MTR could be used as a treatment measure in the development of pro-cognitive drugs.

A study applying graph theory to analyze data from DTI combined with MTR showed that patients with schizophrenia have a weaker globally integrated structural brain network when compared to healthy controls (62). The same study concluded that the frontal hubs had a less central role than in healthy controls, which is in accordance with a reduced structural capacity to integrate information across brain regions. Moreover, a new study combining DTI and resting-state fMRI comparing patients with schizophrenia to healthy controls identified a selective disruption of brain connectivity among central hub regions with a potential communication capacity reduction and brain dynamics alterations (63).

\section{MYELIN DEFICIENCIES IN SCHIZOPHRENIA}

Compelling evidence from several different lines of research has, in recent years, implicated dysfunctional myelin and oligodendrocytes, the cells responsible for wrapping myelin around neuronal axons in the brain, in the pathology of schizophrenia and related psychoses $(22,64-66)$. Sources of evidence include genetics and pharmacogenetic studies, post-mortem studies, and as briefly reviewed in the previous subsections of brain imaging studies, particularly DTI studies.

Normal myelination starts in the late part of fetal life and occurs most rapidly during the first 2 years after birth, but continues to adulthood in a region- and brain matter-specific manner $(22,65$, 67). Initial myelination occurs subcortically, thus increasing the conduction velocities across different brain regions while leaving the intra-cortical portion of the axon unmyelinated during childhood (65). Interestingly, maturation of white matter in the prefrontal cortex and in fronto-temporal tracts occurs later, in late adolescence and early adult life, coinciding in time with the peak age of schizophrenia onset (1). Possibly, disturbances in the 
maturation of myelin around the end of the myelination stage could be one of the events contributing to the peak debut incidence of schizophrenia in this age group (66). The prefrontal cortex is one of the regions most robustly implicated in schizophrenia pathology, and working memory performance, which engages this region, has been found to be positively associated with the level of white matter maturation (67). Later intra-cortical myelination occurs for the most part in adulthood and is associated with the refinement of cognitive functions and brain plasticity (65). Importantly, myelination is a dynamic process, and oligodendrocyte progenitor cells continue to differentiate throughout life (68). In schizophrenia, intra-cortical myelin deficits seems to be more pronounced than subcortical deficits, which have been found to be more strongly associated with the duration of illness. Indeed, evidence suggests that myelin integrity is closely related to both cognitive functioning and to the symptoms of a variety of psychiatric and neurological disorders $(22,46)$.

Alterations particularly in dopaminergic transmission $(69,70)$, and also in the glutamatergic system, $(11,71)$ have been robustly implicated in the pathology of schizophrenia for several decades. Glutamatergic N-methyl-D-aspartate (NMDA) receptor antagonists, such as phencyclidine (PCP) and ketamine, have the potential to induce not only positive symptoms of psychosis but also negative symptoms and cognitive dysfunction resembling those seen in schizophrenia $(11,71)$. This has given rise to the NMDA receptor hypofunction hypothesis of schizophrenia $(21,72)$. The hypothesis has been extensively investigated in animal models but several limitations related to how well evidence from preclinical studies translate into schizophrenia patients have been pointed to (72). Seemingly, paradoxically another model of schizophreniarelated cognitive dysfunction is that of glutamatergic hyperactivity (73). The model is based on other observations of increased prefrontal glutamate release following NMDA receptor antagonism. The apparent paradoxical glutamate findings might be explained by different NMDA receptor properties related to the different locations and/or sub-compositions of the different NMDA receptors as elaborated by Zhou et al. (74). Interestingly, there are several points of convergence between myelin deficits and neurotransmitter alterations. Firstly, glutamate is excitotoxic when in excess, and oligodendrocyte progenitor cells display great vulnerability for glutamatergic excitotoxicity (68). Increased glutamate levels have been found in some phases of schizophrenia (75-77). Secondly, there is emerging evidence that dysfunctional myelin and oligodendrocytes could increase striatal dopamine levels, see Ref. (22) for details. One example could be that if glutamatergic projections from the prefrontal cortex to brainstem areas suffer from myelin damage, this might lead to lower excitatory input at inhibitory brainstem GABAergic interneurons, resulting in less inhibition of dopaminergic mesolimbic projections and consequently striatal hyperdopaminergia as outlined by Schwartz et al. (78).

\section{MYELIN AS DRUG TARGET FOR PRESENT ANTIPSYCHOTICS}

Animal studies suggest that myelin-protecting and oligodendrocytestimulating properties may be a therapeutically relevant mechanism of action for at least some SGAs $(61,79,80)$. In a DTI study of schizophrenia patients in exacerbation, Garver et al. (81) found increased diffusibility consistent with decreased myelin integrity during acute psychosis. After initial examination, patients were treated with the SGAs risperidone or ziprasidone, or the FGA haloperidol, with partial restoration of myelin integrity after 4 weeks in the subgroup that responded to treatment. Bartzokis et al. found higher volumes of intra-cortical myelin in schizophrenia patients treated with oral risperidone compared to those treated with the FGA fluphenazine decanoate (82). In a recent study by the same group, the long acting injection formulation of risperidone was associated with increased intra-cortical myelin volume compared to the oral formulation of the same compound (64). Myelin primarily consists of lipids, particularly cholesterol, which are mainly synthesized de novo in the brain. Interestingly, several antipsychotic agents have been demonstrated to directly induce lipogenesis through the sterol regulatory element binding protein (SREBP) system, and these lipogenic effects have been suggested to contribute to myelin-stimulating effects of antipsychotic agents (83-85). In this regard, it is highly interesting that clozapine, with its superior clinical efficacy, is also among the antipsychotics associated with the most pronounced metabolic adverse effects; in fact, a correlation between clinical improvement and increase in serum lipid levels has repeatedly been demonstrated (86-88). Summing up, a small but consistent body of evidence indicates that some current SGAs have positive effects on myelin volume, with possible distinctions among drugs and drug formulations.

\section{OTHER POTENTIAL "MYELIN-ENHANCING" TREATMENT OPTIONS}

In a clinical randomized controlled trial (RCT) by Amminger et al. (89), a markedly decreased progression rate to psychosis was found in at risk subjects receiving high-dose polyunsaturated fatty acids (PUFAs). PUFAs are involved in the myelination process, and peripheral PUFA levels have been found to be decreased in schizophrenia $(90,91)$. A recent DTI study in early-phase psychosis patients found an association between level of PUFAs in peripheral erythrocytes and white matter integrity (90). Possibly, PUFA distribution is altered in patients at risk for psychosis, with a link between PUFA levels and white matter integrity. Free radicals can damage membrane PUFAs, and disturbances in fatty acids and membrane phospholipid identified in patients with schizophrenia may be caused by increased oxidative stress according to a review by Yao and Keshavan (92). The same authors point to disruption of antioxidative systems related to schizophrenia, with reduced amounts of non-enzymatic plasma antioxidant components [e.g., albumin, bilirubin, uric acid, ascorbic acid (vitamin C), $\alpha$-tocopherol (vitamin E)], see also the recent clinical study by Zhang et al. demonstrating a reduced plasma total antioxidant status in a sample of schizophrenia patients (93). Interestingly, PUFAs also have mild anti-inflammatory effects, see Section "Additional Drugs with Anti-Inflammatory Action as Add-on Treatments for Patients with Schizophrenia.”

\section{INFLAMMATION AND IMMUNOLOGY IN SCHIZOPHRENIA IMPLICATING INFLAMMATORY SYSTEMS IN SCHIZOPHRENIA}

Several findings point to a link between inflammatory processes and the pathophysiology of schizophrenia: (1) activated peripheral inflammatory system and neuroinflammation in patients with schizophrenia $(94,95),(2)$ evidence from genetic studies of 
correlation between schizophrenia and genes encoding for different components of the immune system (96-98), (3) post-mortem studies demonstrating up-regulated immune genes in the prefrontal cortex of patients with schizophrenia (99), (4) findings that the raised risk of schizophrenia seen after maternal infections acts via immunological mechanism (23), and (5) psychotic symptoms and cognitive dysfunction caused by immunological neurological syndromes (100), e.g., the interesting line of pathophysiological evidence based on findings in autoimmune synaptic encephalitis (limbic encephalitis), where antibody formation against NMDA receptors is associated with a wide range of psychiatric symptoms, in some patients also with syndromes resembling schizophrenia (100). Binding of NMDA antibodies has been found predominantly in the hippocampus (101). Also, in systemic autoimmune disorders such as systemic lupus erythematosus (SLE), patients can suffer from various psychiatric syndromes, but the pathophysiology has yet to be characterized in detail (102). A recent remarkable finding is that the levels of soluble receptors for the pro-inflammatory cytokine tumor necrosis factor (TNF)- $\alpha$ correlates with function in patients with schizophrenia compared to healthy individuals (103), the same study also found increased levels of TNF- $\alpha$ in the treatment resistant group compared to treatment responders.

In the following sections, we highlight some of the main findings related to inflammation/immunology and schizophrenia, with the specific purpose of evaluating the status of immunemodulating treatment with cognitive-enhancing effects.

\section{CYTOKINES}

In the context of inflammatory changes in schizophrenia, the majority of findings stem from the innate system, but components of the adaptive immunology system have also been implicated. The macrophages of the innate system induce the release of acutephase proteins [e.g., C-reactive protein (CRP) from hepatocytes] as well as producing and releasing cytokines (97), all markers of inflammation (104). Cytokines are also produced by peripherally activated endothelial cells and monocyte-derived dendritic cells (97).

\section{PERIPHERAL INFLAMMATORY FINDINGS IN SCHIZOPHRENIA}

Multiple studies have shown low-grade disturbances in the peripheral inflammatory system in patients with schizophrenia, see recent reviews (105-107). Pro-inflammatory changes include elevated serum measures of pro-inflammatory cytokines [interleukin (IL)-1 $\beta$, IL-6, IL-8, TNF- $\alpha$ ] and other pro-inflammatory factors [prostaglandin $\mathrm{E}_{2}\left(\mathrm{PGE}_{2}\right), \mathrm{CRP}$ ] and elevated monocyte counts and activated immune cells have been associated with schizophrenia (108). Interestingly, some cytokines [IL-12, IFN- $\gamma, \mathrm{TNF}-\alpha$, soluble IL-2 receptor (sIL-2R)] may be trait markers for schizophrenia, while others are raised during phases of intensified symptoms (IL-1 $\beta$, IL-6, and TGF- $\beta$ ) $(106,108)$. Furthermore, some anti-inflammatory substances are elevated in subgroups of patients with schizophrenia [soluble IL-1 receptor antagonist (sIL-1RA), soluble IL-2 receptor antagonist (sIL-2RA), soluble TNF receptors (sTNFRs)1, sTNFR2 (109), IL-10 (a cytokine with anti-inflammatory properties), and transforming growth factor (TGF)- $\beta$ ] (105). A review (110) identified decreased levels of IL-2 in patients with schizophrenia. IL-2 serves important functions in T-cell-mediated immunologic reactions. Although the findings of disturbances in the peripheral inflammatory system are not without inconsistencies, and the measurements of cytokines are sensible to a wide range of confounders (e.g., the influence of antipsychotic medication and metabolic status), there is firm evidence for a mixed picture of peripheral pro- and anti-inflammatory changes in a large proportion of patients with schizophrenia.

\section{CENTRAL INFLAMMATORY FINDINGS IN PATIENTS WITH SCHIZOPHRENIA}

Brain neuroinflammation, in contrast to inflammation in other parts of the body, does not lead to leukocyte recruitment, but is characterized by activated microglia, the mononuclear phagocytes of the brain (111). Microglia develop from primitive myeloid progenitors, and have various roles in the developing human brain including synaptic pruning, remodeling of axons, neuronal differentiation, and programed cell death (112). PET studies using (R) [11C]PK11195 $(95,113)$ have found microglial activation in schizophrenia, in addition to post-mortem studies demonstrating increased density and activation of microglia, though some of these studies have yielded conflicting evidence (112). Activated microglia have increased levels of the translocator protein (TPSO) located at the mitochondrial membrane, and the binding of TPSO to the $(\mathrm{R})[11 \mathrm{C}] \mathrm{PK} 11195$ is utilized in PET studies as a measure of neuroinflammation, while other PET ligands for activated microglia are under development (113). Free-water imaging (114) is another mode of neuroinflammation imaging, and studies using this novel method have indicated widespread brain inflammation and early signs of neurodegeneration in first-episode patients with schizophrenia (115).

\section{Microglia, astrocytes, and the kynurenine pathway}

Activated microglia have many important functions besides phagocytosis, including cytokine production (IL-1 $\beta$, IL-12, and TNF- $\alpha)(94,111)$, most importantly crosstalk with the serotonin and glutamate neurotransmitter systems, involving the kynurenine pathway (116). Activated microglia also induce functional changes in brain astrocytes, which release IL-6, IL-10, and TGF- $\beta$ (94). In the presence of pro-inflammatory cytokines, e.g., IFN$\gamma$ and TNF- $\alpha$, tryptophan catabolism to kynurenins in microglia and astrocytes is induced, resulting in the production of quinolinic acid (QUIN) in microglia and KYNA in astrocytes. QUIN is an NMDA agonist and potentially excitotoxic, while KYNA is an NMDA antagonist and also blocks the $\alpha 7$ nicotinic acetylcholine receptor $(\alpha 7 \mathrm{nAChR})(94,116)$. Figure 1 summarizes major points of the activated inflammatory responses in schizophrenia. The demonstration of elevated levels of KYNA in the cerebrospinal fluid (CSF) of patients with schizophrenia by two independent groups $(117,118)$ in 2001 boosted research in brain inflammatory-related processes implicated in schizophrenia. Elevation of KYNA in the CSF and prefrontal cortex in patients with schizophrenia is now an established finding, and is probably a consequence of peripheral inflammation according to a recent review by Schwarcz et al. (119). Elevated levels of KYNA are associated with decreased cognitive performance in animal models, including altered pre-pulse inhibition of the auditory startle 


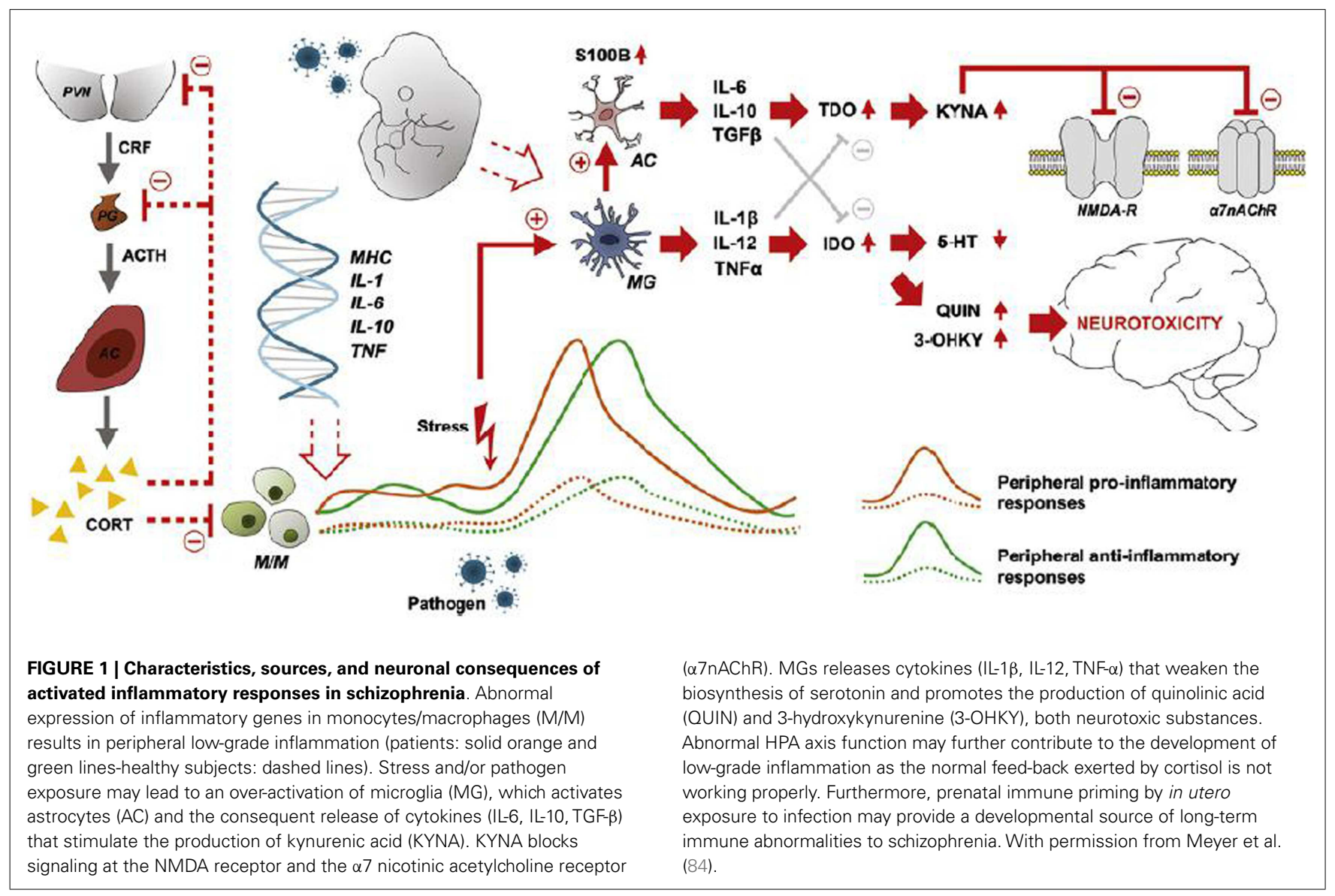

response, deficits of working memory, and attentional set-shifting paradigms $(120,121)$, while reducing KYNA resulted in improved cognitive performance in a wide range of tasks (121). Adding to this, the kynurenic pathway also offers a possible explanation of how stress induces psychotic symptoms and cognitive dysfunction in schizophrenia by linking increased levels of glucocorticoids to the production of kynurenine in liver, subsequently converted to KYNA in the brain (121). The kynurenic pathway offers several potential drug targets for the reduction of brain KYNA levels, which could improve cognitive function in schizophrenia. Candidate pharmacological agents related to schizophrenia treatment block, e.g., the enzyme kynurenine aminotransferase (KAT), which transforms kynurenine into KYNA. Most KYNA-lowering drugs still lack behavioral data (122), while cerebrolysin, a peptidergic drug manufactured from purified porcine brain preparations, which lower brain tissue KYNA levels in vitro (123) also have been found to improve cognition (124). Interestingly, in a double blind RCT of patients with schizophrenia cerebrolysin (intravenous infusion) as add-on treatment to risperidone was found to improve scores at the Wechsler Adult Intelligence Scale and the Wechsler Memory Scale (124). Cerebrolysin is generally welltolerated (125) and has also demonstrated pro-cognitive effects in patients with dementia $(126,127)$ and traumatic brain injury (128). In another recent study, D-cycloserine (DSC), a partial agonist at the glycine site of the NMDA receptor, was also found to reduce the levels of KYNA in human post-mortem frontal cortex homogenates by dose-dependently blocking KAT (129). DSC has also been found to improve memory consolidation and to reduce delusions in combination with cognitive behavioral therapy (130).

\section{IL-1 $\beta$, S100B, BDNF}

In addition to elevated KYNA/QUIN, other aspects of an activated brain immune system can also have clinically important effects in schizophrenia. The proinflammatory cytokine IL-1 $\beta$ has been linked to glutamatergic excitotoxicity (131), and close dynamic interactions between IL- $1 \beta$ and the NMDA receptor was the recently demonstrated (132). Pro-inflammatory cytokines (e.g., IL-1) are also candidate causal agents implicated in the cerebral myelin damages discussed above, see $(133,134)$. The protein $\mathrm{S} 100 \mathrm{~B}$, produced by astrocytes, is a marker of astrocyte activation. Serving as an example of the pleiotropic effects associated with many inflammatory factors at low concentration, S100B has beneficial effects, limiting microglia activation, stress-related neuronal damage, and increase glutamate uptake by astrocytes, while at higher concentration it has detrimental effects, including induction of microglial TNF- $\alpha$ secretion and induced production of, e.g., COX2/PGE-2, IL-1 $\beta$, etc. (135). A meta-analysis concluded that serum levels of $\mathrm{S100B}$ may be elevated in schizophrenia, and disruptions of the blood-brain barrier (BBB) and/or active secretion by astrocytes were suggested as possible causes (136).

The neurotrophin BDNF is among the substances secreted by immune cells during inflammation and immune responses (137), 
and an inverse relationship between levels of BDNF and certain cytokines has been found (138). BDNF has been implicated in widespread processes relevant to the pathophysiology of schizophrenia including neurodevelopment, synapse regulation, and neuroplasticity, as well as effects on cognition, see for example (138-140). BDNF has been found to be reduced in schizophrenia in both drug-naïve and chronic patients, although findings are not entirely consistent across studies. Furthermore, an association has been found between reduced neurocognitive function and reduced serum BDNF levels (139). BDNF interacts with dopaminergic, glutamatergic, and serotonergic systems in the brain, see Nurjono et al. (138) for a recent update. Regarding BDNF as a drug target, FGAs have been reported to lower peripheral BDNF, whereas SGAs either have no effect or increase BDNF, while antidepressants have been shown to increase BDNF (140).

\section{STRUCTURAL AND FUNCTIONAL CORRELATES OF INFLAMMATORY DISTURBANCES IN PATIENTS WITH SCHIZOPHRENIA}

Structural brain alterations associated with immune-related genetic polymorphisms were recently reviewed by Fineberg and Ellman (107). The review identified associations between variability in the IL-1 gene complex and white and gray matter volume reductions in temporal and frontal brain regions, together with enlarged ventricles in patients with schizophrenia. Furthermore, this review discussed associations of IL-1 gene variations with decreased dorsolateral prefrontal function during different neurocognitive tasks (107). In another review, Meyer (105) found evidence for a positive correlation between the severity of cognitive deficits and the peripheral levels of IL-1 $\beta$, IL-6, TNF- $\alpha$, CRP, and S100B. While the correlation of the inflammatory disturbances with specific cognitive effects is not clarified in patients with schizophrenia, findings from animal studies and studies in non-schizophrenic individuals reveal associations of inflammatory disturbances with executive function, sustained attention, and working memory according to the review by Meyer et al. (105).

\section{ANTI-INFLAMMATORY EFFECTS OF ANTIPSYCHOTIC DRUGS}

Monji et al. (141) recently reviewed studies (mostly in vitro and animal studies) concerning the capability of antipsychotic drugs to influence activated microglia. The review identified several studies showing that antipsychotic drugs significantly reduce the secretion of TNF- $\alpha$, nitric oxide, IL- $1 \beta$, and IL- 2 from activated microglia. Furthermore, some drugs were found to have stronger inhibitory effects, e.g., risperidone, which inhibited the secretion of several cytokines from activated microglia more than haloperidol, and indications of clozapine-specific effects have also been reported. Moreover, in the context of the kynurenine pathway, one animal study demonstrated that chronic treatment with antipsychotic drugs reduces brain KYNA (142). Meyer et al. (94) reviewed the influence of antipsychotic treatment on peripheral cytokines in clinical populations and found that antipsychotics reduced the level of proinflammatory cytokines (IL-1 $\beta$, IL-6, sIL-6R, TNF- $\alpha$ ) while increasing peripheral production of anti-inflammatory substances such as (sIL-1RA, sIL-2R and IL-10). Here, SGAs seemed to have the most pronounced effects and a possible relation between the ability to normalize immune function and clinical effects were identified. Brain imaging studies investigating antipsychotic drug treatment in brain imaging paradigms capable of showing effects on neuroinflammation (e.g., PET/“free water" MRI) would truly improve this field of research, but we have not been able to identify any such studies.

\section{THE EFFECTS OF ANTI-INFLAMMATORY/IMMUNE-MODULATING DRUGS IN THE TREATMENT OF SCHIZOPHRENIA Non-steroid anti-inflammatory drugs}

Based on the notion of activated immune responses in the brain and/or peripheral tissues, a few clinical studies have evaluated the effects of non-steroid anti-inflammatory drugs (NSAIDs) in schizophrenia. The pooled effects size in reducing total Positive and Negative Syndrome Scale (PANSS) score according to a recent meta-analysis of the effect of add-on treatment with NSAIDs [eight studies, two with aspirin $(n=270)$, six with celecoxib $(n=504)]$ to different antipsychotics showed non-significant benefit over placebo (143). Treatment with aspirin alone was superior to placebo, while treatment with celecoxib was not; these conclusions were also drawn in a meta-analysis of Sommer et al. (144). When the studies were categorized according to disease phase, the pooled analyses of all eight studies revealed positive effects of NSAIDs vs. placebo for first-episode patients. The authors concluded that the present data do not lend significant support to NSAIDs as add-on therapy to antipsychotic treatment for patients with schizophrenia. Another review agreed that indiscriminately suppressing inflammation seems not to be the optimal way of treating immunological disturbances associated with schizophrenia, and that treatment should aim at reversing glial loss, upregulating beneficial microglial activation and proliferation (MAP) together with other neuroprotective measures, while ideally downregulating harmful aspects of MAP (135). At present, studies more precisely aiming to elucidate the putative pro-cognitive effects of treatment with NSAIDs in patients with schizophrenia are lacking, although non-significant effects were demonstrated in a small study (145).

\section{Erythropoietin}

Erythropoietin (EPO) is a cytokine with several identified functions in the brain (146). In a 12-week, placebo-controlled study $(n=39)$ with stable schizophrenia patients, treatment with recombinant human EPO (40000 IU/week) improved neurocognitive function compared to placebo in the domains of delayed memory, language-semantic fluency, attention and perseverative errors (147). An evaluation of gray matter development in the same study showed that gray matter loss was significantly less pronounced in the group treated with EPO (148). Animal studies have supported a pro-cognitive effect of EPO treatment (146). A systematic review identified multiple putative beneficial brain targets of EPO treatment, e.g., modulation of inflammation, neuroprotection, neurotransmission regulation, effects on $\mathrm{BBB}$ permeability, but the use of EPO can be limited by adverse effects such as thrombosis and cancer (149). EPO has also been found to improve cognitive function in studies of patients with Parkinson's disease (150) and multiple sclerosis (151).

\section{Minocycline}

The tetracycline antibiotic drug minocycline has also been tested as an add-on treatment for patients with schizophrenia, based on 
evidence from animal studies that showed minocycline to have multiple actions including inhibition of microglial activation and the attenuation of adaptive immunity through the reduction of activity and expression of matrix metalloproteinases (MMPs). MMPs enable T-cells to migrate through the BBB by altering its permeability, a process associated with myelin degradation (152). In a placebo-controlled, 6-month trial in patients with schizophrenia (54 patients receiving $200 \mathrm{mg}$ minocycline and 26 patients receiving placebo), cognitive function (and negative symptoms) improved significantly in the minocycline-treated group, particularly in the domains of working memory, cognitive flexibility, and planning (153). Chaudry et al. (154) reported the results of a 1-year RCT of 155 early schizophrenia patients performed in Brazil and Pakistan, where minocycline reduced negative symptoms (adjusted difference 95\% confidence interval 1.55-5.51 at the PANSS negative subscale), but no significant effects of treatment were found in tests for cognitive function. The meta-analysis of Sommer et al. (144) identified four RCT studies with $n=182$ patients given minocycline, and $n=166$ on placebo, the effects on cognition were not reported, but no significant effects on overall symptom severity were identified.

\section{Additional drugs with anti-inflammatory action as add-on treatments for patients with schizophrenia}

The meta-analysis by Sommer et al. (144) also investigated the effect of additional anti-inflammatory treatments. The outcome measure was the mean change in PANSS (155) or the Brief Psychiatric Rating Scale (156), and significant improvements of treatment with $n$-acetylcysteine $(n=140)$, aspirin $(n=270)$, and estrogens ( $n=262$ ) were identified, while studies with davunetide and PUFAs (eicosapentanoic acid and docosahexanoic acids) did not show significant effects.

\section{SUMMING UP PRO-COGNITIVE EFFECTS OF IMMUNOMODULATING/ANTI-INFLAMMATORY DRUG TREATMENT FOR PATIENTS WITH SCHIZOPHRENIA: CRITICAL METHODOLOGICAL PROBLEMS REMAIN}

The involvement of inflammatory/immunological factors in the pathophysiology of a large portion of patients with schizophrenia is well established through different lines of research, and data point to several links between these factors and cognitive dysfunction. Presently, many drugs with anti-inflammatory or immunomodulatory action have been tested (as add-on to antipsychotic treatment) for patients with schizophrenia, and while some have shown positive effects for global schizophrenia symptoms, the effects on cognition were not possible to assess in the recent meta-analysis by Sommer et al. (144), as only 5 of 26 included studies reported data on cognitive tests and the heterogeneity of the cognitive tasks made it impossible to quantitatively review the effects. Furthermore, as highlighted by Sommer et al. the drugs tested that were shown to improve the symptoms of schizophrenia ( $N$-acetylcysteine, estrogens, aspirin) have broad mechanisms of action, and it is not at all demonstrated that the improved symptoms are caused by anti-inflammatory actions. A further critical question to address in future drug research will be to establish reliable brain imaging methods to quantitatively assess neuroinflammation, as the levels of peripheral cytokines are only an indirect measure of brain neuroinflammation. PET studies with new ligands that specifically target activated microglia and the "free-water" MRI scanning seem promising, but extensive development remains before these methods are ready as outcome measures in drug discovery studies.

\section{SUMMARY AND CONVERGENCE}

At present, pharmacological treatment of schizophrenia relies on antipsychotic drugs, which predominantly relieve positive psychotic symptoms and have little effect on the cognitive dysfunctions restricting the functional level of patients. However, recent developments in brain imaging, including novel specific PET ligands and MRI paradigms specifically investigating myelin integrity, neurotransmitter levels, and neuroinflammation, facilitate the unraveling of mechanisms underlying cognitive dysfunction in schizophrenia. Accumulating evidence supports a combined model including all these areas of pathology underlying the cognitive deficits in schizophrenia, schematically exemplified by Figure 2 for the interplay between prefrontal cortex, striatum, and brain stem. This joint model represents several potential procognitive drug targets at the level of neurotransmitters, lipids, and inflammatory markers, however, no current drugs aimed at these targets are so far definitely proven to be clinically useful as pro-cognitive drugs for patients with schizophrenia. Studies concerning immunomodulatory drugs, including EPO, minocycline, celecoxib, aspirin, estrogens, $n$-acetylcysteine have shown promising results in single studies, but have not yielded straightforward support for the use in clinical practice to enhance cognition.

\section{FUTURE PERSPECTIVES}

Drugs that would reduce brain levels of KYNA (e.g., KAT inhibitors) are expected to improve cognitive dysfunctions in schizophrenia based on animal studies, but remain to be developed for clinical use. The possibility of pro-cognitive effects of drugs that have been used to treat other medical conditions for years, e.g., EPO, minocycline, and aspirin is attractive, also because the safety profile of many of these drugs are well known in neurological patients populations, reducing the costs of introducing the drugs as cognitive enhancers for schizophrenia patients. Several critical questions currently constraining progress remain to be solved, however. Firstly, uniformly accepted and standardized cognitive assessments for repeated measures must be agreed on for pro-cognitive drug studies in schizophrenia patients. Secondly, the refinement of brain imaging methods unto sufficient reliability and specificity (e.g., measuring neuroinflammation and myelin integrity) for use as outcome measures in pro-cognitive drug is essential for studies of putative cognition enhancers in humans. Thirdly, and at least of prominent importance in the field of further developments of pro-cognitive glutamatergic substances are the problems of translating findings in animal studies to human drug treatment.

However, even though the process of developing novel pharmacological agents is highly sophisticated, identifying novel treatment targets through thorough clinical and preclinical studies remains pivotal in the continued search for improved treatment of schizophrenia. The convergence of a disordered inflammatory system, disturbances in myelination/oligodendrocyte function, 


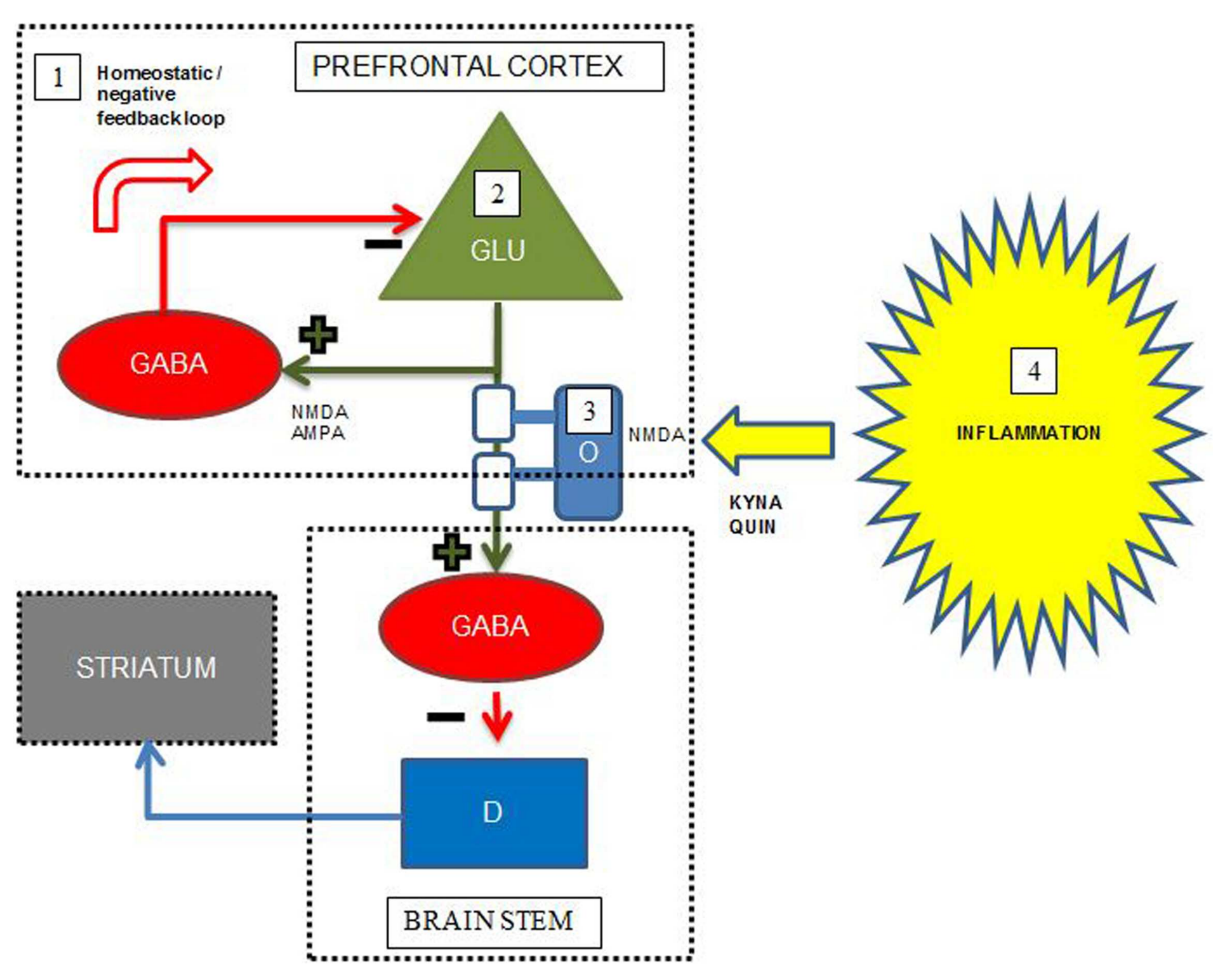

FIGURE 2 | Simplified putative interplay between selected neurotransmitters, oligodendrocytes, and inflammation in the pathology of cognitive dysfunctions in schizophrenia. Green cell = excitatory pyramidal glutamatergic (GLU) neuron; red cell = inhibitory GABAergic (GABA) interneuron; blue cell = modulatory dopaminergic (D) neuron; light blue cell = oligodendrocyte $(\mathrm{O})$ with white myelin sheets enclosing the pyramidal cell axon; KYNA = kynurenic acid,

QUIN = quinolinic acid. The figure displays some putative points of convergence between neurotransmitters, myelin, and neuroinflammation relevant to the cognitive dysfunctions of schizophrenia. Details are elaborated in the text. (1) In the prefrontal cortex, abnormal NMDA functioning on, and/or deficient GABA release and reuptake in a subset of GABAergic interneurons result in deficient negative feedback on pyramidal glutamatergic neurons, which may lead to glutamatergic hyperactivity, excitotoxicity, and disruption of coordinated firing of pyramidal cells. (2) Deficient glutamatergic neuronal activity leads to decreased excitatory input on GABAergic interneurons terminating on dopaminergic projections to striatum, leading to striatal hyperdopaminergia. The hyperdopaminergia may inversely influence cognitive functions located in the prefrontal cortex. (3) Reduced myelin integrity may inversely influence glutamatergic signaling leading to the same consequences as in the point above. Oligodendrocytes express NMDA receptors and are thus vulnerable for excitotoxicity from excess glutamate and QUIN. (4) During inflammation QUIN is produced in microglia and KYNA in astrocytes. QUIN is an NMDA agonist and potentially excitotoxic, while KYNA is an NMDA antagonist that could induce cognitive dysfunctions consistent with the NMDA receptor hypofunction hypothesis of schizophrenia. Adapted with permission from Lisman et al. (72) and Takahashi et al. (102). and transmitter dysfunctions in schizophrenia open new paths for pro-cognitive drug discovery with putative large functional improvements to be achieved for patients with schizophrenia.

\section{ACKNOWLEDGMENTS}

Parts of the research were funded by grants to Erik Johnsen from the Research Council of Norway, project no. 213727, and several grants from Helse Vest. Parts of the research were funded by an ERC Advanced Grant and by the NORMENT SFF from the Research Council of Norway to Kenneth Hugdahl and Silje Skrede.

\section{REFERENCES}

1. Tandon R, Nasrallah HA, Keshavan MS. Schizophrenia, "just the facts" 4. Clinical features and conceptualization. Schizophr Res (2009) 110:1-23. doi:10.1016/j.schres.2009.03.005

2. World Health Organization. The World Health Report 2001 - Mental Health: New Understanding, New Hope. Geneva: WHO (2001).
3. Ustun TB, Rehm J, Chatterji S, Saxena S, Trotter R, Room R, et al. Multipleinformant ranking of the disabling effects of different health conditions in 14 countries. WHO/NIH Joint Project CAR Study Group. Lancet (1999) 354:111-5. doi:10.1016/S0140-6736(98)07507-2

4. Tandon R. Antipsychotics in the treatment of schizophrenia: an overview. JClin Psychiatry (2011) 72(Suppl 1):4-8. doi:10.4088/JCP.10075sul.01

5. Miyamoto S, Miyake N, Jarskog LF, Fleischhacker WW, Lieberman JA. Pharmacological treatment of schizophrenia: a critical review of the pharmacology and clinical effects of current and future therapeutic agents. Mol Psychiatry (2012) 17(12):1206-27. doi:10.1038/mp.2012.47

6. Shen WW. A history of antipsychotic drug development. Compr Psychiatry (1999) 40:407-14. doi:10.1016/S0010-440X(99)90082-2

7. Leucht S, Cipriani A, Spineli L, Mavridis D, Orey D, Richter F, et al. Comparative efficacy and tolerability of 15 antipsychotic drugs in schizophrenia: a multiple-treatments meta-analysis. Lancet (2013) 382(9896):951. doi:10.1016/ S0140-6736(13)60733-3

8. Meltzer HY. Update on typical and atypical antipsychotic drugs. Annu Rev Med (2012) 64:393-406. doi:10.1146/annurev-med-050911-161504

9. Meltzer HY, Massey BW. The role of serotonin receptors in the action of atypical antipsychotic drugs. Curr Opin Pharmacol (2011) 11:59-67. doi:10.1016/j. coph.2011.02.007 
10. Meltzer HY, Matsubara S, Lee JC. Classification of typical and atypical antipsychotic drugs on the basis of dopamine D-1, D-2 and serotonin2 pKi values. J Pharmacol Exp Ther (1989) 251:238-46.

11. Kantrowitz JT, Javitt DC. N-methyl-d-aspartate (NMDA) receptor dysfunction or dysregulation: the final common pathway on the road to schizophrenia? Brain Res Bull (2010) 83:108-21. doi:10.1016/j.brainresbull.2010.04.006

12. Gray JA, Roth BL. The pipeline and future of drug development in schizophrenia. Mol Psychiatry (2007) 12:904-22. doi:10.1038/sj.mp.4002062

13. Gray JA, Roth BL. Molecular targets for treating cognitive dysfunction in schizophrenia. Schizophr Bull (2007) 33:1100-19. doi:10.1093/schbul/sbm074

14. Demjaha A, Egerton A, Murray RM, Kapur S, Howes OD, Stone JM, et al. Antipsychotic treatment resistance in schizophrenia associated with elevated glutamate levels but normal dopamine function. Biol Psychiatry (2013). doi:10.1016/j.biopsych.2013.06.011

15. Green MF. What are the functional consequences of neurocognitive deficits in schizophrenia? Am J Psychiatry (1996) 153:321-30.

16. Palmer BW, Dawes SE, Heaton RK. What do we know about neuropsychological aspects of schizophrenia? Neuropsychol Rev (2009) 19:365-84. doi:10.1007/s11065-009-9109-y

17. Chou H-H, Twamley E, Swerdlow N. Towards medication-enhancement of cognitive interventions in schizophrenia. In: Geyer MA, Gross G, editors. Novel Antischizophrenia Treatments. Berlin: Springer (2012). p. 81-111.

18. Lameh J, McFarland K, Ohlsson J, Ek F, Piu F, Burstein E, et al. Discovery of potential antipsychotic agents possessing pro-cognitive properties. Naunyn Schmiedebergs Arch Pharmacol (2012) 385:313-23. doi:10.1007/s00210-0110702-2

19. Insel TR, Voon V, Nye JS, Brown VJ, Altevogt BM, Bullmore ET, et al. Innovative solutions to novel drug development in mental health. Neurosci Biobehav Rev (2013) 37(10 Pt 1):2438-44. doi:10.1016/j.neubiorev.2013.03.022

20. Williams M. Productivity shortfalls in drug discovery: contributions from the preclinical sciences? J Pharmacol Exp Ther (2011) 336:3-8. doi:10.1124/jpet. 110.171751

21. Marek GJ, Behl B, Bespalov AY, Gross G, Lee Y, Schoemaker H. Glutamatergic (N-methyl-d-aspartate receptor) hypofrontality in schizophrenia: too little juice or a miswired brain? Mol Pharmacol (2010) 77:317-26. doi:10.1124/mol. 109.059865

22. Takahashi N, Sakurai T, Davis KL, Buxbaum JD. Linking oligodendrocyte and myelin dysfunction to neurocircuitry abnormalities in schizophrenia. Prog Neurobiol (2011) 93:13-24. doi:10.1016/j.pneurobio.2010.09.004

23. Anderson G, Berk M, Dodd S, Bechter K, Altamura AC, Dell'Osso B, et al. Immuno-inflammatory, oxidative and nitrosative stress, and neuroprogressive pathways in the etiology, course and treatment of schizophrenia. Prog Neuropsychopharmacol Biol Psychiatry (2013) 42:1-4. doi:10.1016/j.pnpbp. 2012.07.016

24. Millan MJ, Agid Y, Brüne M, Bullmore ET, Carter CS, Clayton NS, et al. Cognitive dysfunction in psychiatric disorders: characteristics, causes and the quest for improved therapy. Nat Rev Drug Discov (2012) 11:141-68. doi: $10.1038 / \mathrm{nrd} 3628$

25. Kahn RS, Keefe RE. Schizophrenia is a cognitive illness: time for a change in focus. JAMA Psychiatry (2013) 70(10):1107-12. doi:10.1001/jamapsychiatry. 2013.155

26. Weinberger DR. From neuropathology to neurodevelopment. Lancet (1995) 346:552-7. doi:10.1016/S0140-6736(95)91386-6

27. Caspi A, Reichenberg A, Weiser M, Rabinowitz J, Kaplan Z, Knobler H, et al. Cognitive performance in schizophrenia patients assessed before and following the first psychotic episode. Schizophr Res (2003) 65:87-94. doi:10.1016/S09209964(03)00056-2

28. Gschwandtner U, Aston J, Borgwardt S, Drewe M, Feinendegen C, Lacher $D$, et al. Neuropsychological and neurophysiological findings in individuals suspected to be at risk for schizophrenia: preliminary results from the Basel early detection of psychosis study - Fruherkennung von Psychosen (FEPSY). Acta Psychiatr Scand (2003) 108:152-5. doi:10.1034/j.1600-0447.2003.00157.x

29. Heaton RK, Gladsjo J, Palmer BW, Kuck J, Marcotte TD, Jeste DV. Stability and course of neuropsychological deficits in schizophrenia. Arch Gen Psychiatry (2001) 58:24-32. doi:10.1001/archpsyc.58.1.24

30. Rund BR. A review of longitudinal studies of cognitive functions in schizophrenia patients. Schizophr Bull (1998) 24:425-35. doi:10.1093/oxfordjournals. schbul.a033337
31. Nuechterlein KH, Barch DM, Gold JM, Goldberg TE, Green MF, Heaton RK. Identification of separable cognitive factors in schizophrenia. Schizophr Res (2004) 72:29-39. doi:10.1016/j.schres.2004.09.007

32. Dickinson D, Ramsey ME, Gold JM. Overlooking the obvious: a meta-analytic comparison of digit symbol coding tasks and other cognitive measures in schizophrenia. Arch Gen Psychiatry (2007) 64:532-42. doi:10.1001/archpsyc. 64.5 .532

33. Heinrichs R, Zakzanis K. Neurocognitive deficit in schizophrenia: a quantitative review of the evidence. Neuropsychology (1998) 12:426-45. doi:10.1037/ 0894-4105.12.3.426

34. Wilk CM, Gold JM, Bartko JJ, Dickerson F, Fenton WS, Knable M, et al. Test-retest stability of the repeatable battery for the assessment of neuropsychological status in schizophrenia. Am J Psychiatry (2002) 159:838-44. doi:10.1176/appi.ajp.159.5.838

35. Wilk CM, Gold JM, Humber K, Dickerson F, Fenton WS, Buchanan RW. Brief cognitive assessment in schizophrenia: normative data for the repeatable battery for the assessment of neuropsychological status. Schizophr Res (2004) 70:175-86. doi:10.1016/j.schres.2003.10.009

36. Gold MJ, Queern C, Iannone VN, Buchanan RW. Repeatable battery for the assessment of neuropsychological status as a screening test in schizophrenia I: sensitivity, reliability, and validity. Am J Psychiatry (1999) 156:1944-50.

37. Keefe RS. Should cognitive impairment be included in the diagnostic criteria for schizophrenia? World Psychiatry (2008) 7:22-8. doi:10.1002/j.2051-5545. 2008.tb00142.x

38. Green MF, Kern RS, Braff DL, Mintz J. Neurocognitive deficits and functional outcome in schizophrenia: are we measuring the "right stuff"? Schizophr Bull (2000) 26:119-36. doi:10.1093/oxfordjournals.schbul.a033430

39. Kaneda Y, Jayathilak K, Meltzer HY. Determinants of work outcome in schizophrenia and schizoaffective disorder: role of cognitive function. Psychiatry Res (2009) 169:178-9. doi:10.1016/j.psychres.2008.08.003

40. Laes JR, Sponheim SR. Does cognition predict community function only in schizophrenia? A study of schizophrenia patients, bipolar affective disorder patients, and community control subjects. Schizophr Res (2006) 84:121-31. doi:10.1016/j.schres.2005.11.023

41. Tsang HW, Leung AY, Chung RC, Bell M, Cheung WM. Review on vocational predictors: a systematic review of predictors of vocational outcomes among individuals with schizophrenia: an update since 1998. Aust N Z J Psychiatry (2010) 44:495-504. doi:10.3109/00048671003785716

42. McClure MM, Bowie CR, Patterson TL, Heaton RK, Weaver C, Anderson H, et al. Correlations of functional capacity and neuropsychological performance in older patients with schizophrenia: evidence for specificity of relationships? Schizophr Res (2007) 89:330-8. doi:10.1016/j.schres.2006.07.024

43. Nuechterlein K, Green M, Kern R, Baade L, Barch D, Cohen J, et al. The MATRICS consensus cognitive battery, part 1: test selection, reliability, and validity. Am J Psychiatry (2008) 165:203-13. doi:10.1176/appi.ajp.2007. 07010042

44. Keefe RS, Fox KH, Harvey PD, Cucchiaro J, Siu C, Loebel A. Characteristics of the MATRICS consensus cognitive battery in a 29-site antipsychotic schizophrenia clinical trial. Schizophr Res (2011) 125:161-8. doi:10.1016/j.schres. 2010.09.015

45. Burton CZ, Vella L, Harvey PD, Patterson TL, Heaton RK, Twamley EW. Factor structure of the MATRICS consensus cognitive battery (MCCB) in schizophrenia. Schizophr Res (2013) 146:244-8. doi:10.1016/j.schres.2013.02.026

46. Fields RD. White matter in learning, cognition and psychiatric disorders. Trends Neurosci (2008) 31:361-70. doi:10.1016/j.tins.2008.04.001

47. Puri BK. Progressive structural brain changes in schizophrenia. Expert Rev Neurother (2010) 10:33-42. doi:10.1586/ern.09.142

48. Ellison-Wright I, Bullmore E. Meta-analysis of diffusion tensor imaging studies in schizophrenia. Schizophr Res (2009) 108:3-10. doi:10.1016/j.schres. 2008.11.021

49. Walterfang M, Wood SJ, Velakoulis D, Pantelis C. Neuropathological, neurogenetic and neuroimaging evidence for white matter pathology in schizophrenia. Neurosci Biobehav Rev (2006) 30:918-48. doi:10.1016/j.neubiorev. 2006.02.001

50. Rigucci S, Rossi-Espagnet C, Ferracuti S, De Carolis A, Corigliano V, Carducci $\mathrm{F}$, et al. Comparelli, anatomical substrates of cognitive and clinical dimensions in first episode schizophrenia. Acta Psychiatr Scand (2012) 128:261-70. doi:10.1111/acps.12051 
51. Nazeri A, Mallar Chakravarty M, Felsky D, Lobaugh NJ, Rajji TK, Mulsant $\mathrm{BH}$, et al. Alterations of superficial white matter in schizophrenia and relationship to cognitive performance. Neuropsychopharmacology (2013) 38:1954-62. doi:10.1038/npp.2013.93

52. Ruiz S, Birbaumer N, Sitaram R. Abnormal neural connectivity in schizophrenia and fMRI-brain-computer interface as a potential therapeutic approach. Front Psychiatry (2013) 4:17. doi:10.3389/fpsyt.2013.00017

53. Fornito A, Zalesky A, Pantelis C, Bullmore ET. Schizophrenia, neuroimaging and connectomics. Neuroimage (2012) 62:2296-314. doi:10.1016/j. neuroimage.2011.12.090

54. Pettersson-Yeo W, Allen P, Benetti S, McGuire P, Mechelli A. Dysconnectivity in schizophrenia: where are we now? Neurosci Biobehav Rev (2011) 35:1110-24. doi:10.1016/j.neubiorev.2010.11.004

55. Hugdahl K, Loberg EM, Nygard M. Left temporal lobe structural and functional abnormality underlying auditory hallucinations in schizophrenia. Front Neurosci (2009) 3:34-45. doi:10.3389/neuro.01.001.2009

56. Raichle M. Two views of brain function. Trends Cogn Sci (2010) 14:180-90. doi:10.1016/j.tics.2010.01.008

57. Hugdahl K, Løberg E-M, Nygård M. Left temporal lobe structural and functional abnormality underlying auditory hallucinations. Front Neurosci (2009) 3(1):34-45. doi:10.3389/neuro.01.001.2009

58. Hugdahl K, Rund B, Lund A, Asbjørnsen A, Egeland J, Landrø N, et al. Brain activation measured with fMRI during a mental arithmetic task in schizophrenia and major depression. Am J Psychiatry (2004) 161(2):286-93. doi:10.1176/appi.ajp.161.2.286

59. Alexander A, Lee J, Lazar M, Field A. Diffusion tensor imaging of the brain. Neurotherapeutics (2007) 4:316-29. doi:10.1016/j.nurt.2007.05.011

60. Ongur D, Du F. Probing myelin and axon abnormalities separately in psychiatric disorders using MRI techniques. Front Integr Neurosci (2013) 7:24. doi:10.3389/fnint.2013.00024

61. Kimoto S, Okuda A, Toritsuka M, Yamauchi T, Makinodan M, Okuda H, et al. Olanzapine stimulates proliferation but inhibits differentiation in rat oligodendrocyte precursor cell cultures. Prog Neuropsychopharmacol Biol Psychiatry (2011) 35:1950-6. doi:10.1016/j.pnpbp.2011.07.011

62. van den Heuvel MP, Mandl RC, Stam CJ, Kahn RS, Hulshoff Pol HE. Aberrant frontal and temporal complex network structure in schizophrenia: a graph theoretical analysis. J Neurosci (2010) 30:15915-26. doi:10.1523/JNEUROSCI. 2874- 10.2010

63. van den Heuvel MP, Sporns O, Collin G, Scheewe T, Mandl RC, Cahn W, et al. Abnormal rich club organization and functional brain dynamics in schizophrenia. JAMA Psychiatry (2013) 70:783-92. doi:10.1001/jamapsychiatry.2013. 1328

64. Bartzokis G, Lu PH, Raven EP, Amar CP, Detore NR, Couvrette AJ, et al. Impact on intracortical myelination trajectory of long acting injection versus oral risperidone in first-episode schizophrenia. Schizophr Res (2012) 140:122-8. doi:10.1016/j.schres.2012.06.036

65. Bartzokis G. Neuroglialpharmacology: myelination as a shared mechanism of action of psychotropic treatments. Neuropharmacology (2012) 62:2137-53. doi:10.1016/j.neuropharm.2012.01.015

66. Catts VS, Fung SJ, Long LE, Joshi D, Vercammen A, Allen KM, et al. Rethinking schizophrenia in the context of normal neurodevelopment. Front Cell Neurosci (2013) 7:60. doi:10.3389/fncel.2013.00060

67. Fields RC, Aft RL, Gillanders WE, Eberlein TJ, Margenthaler JA. Treatment and outcomes of patients with primary breast sarcoma. Am J Surg (2008) 196:559-61. doi:10.1016/j.amjsurg.2008.06.010

68. Walterfang M, Velakoulis D, Whitford TJ, Pantelis C. Understanding aberrant white matter development in schizophrenia: an avenue for therapy? Expert Rev Neurother (2011) 11:971-87. doi:10.1586/ern.11.76

69. Howes OD, Kapur S. The dopamine hypothesis of schizophrenia: version III the final common pathway. Schizophr Bull (2009) 35:549-62. doi:10.1093/ schbul/sbp006

70. Howes OD, Kambeitz J, Kim E, Stahl D, Slifstein M, Abi-Dargham A, et al. The nature of dopamine dysfunction in schizophrenia and what this means for treatment. Arch Gen Psychiatry (2012) 69:776-86. doi:10.1001/ archgenpsychiatry.2012.169

71. Snyder MA, Gao WJ. NMDA hypofunction as a convergence point for progression and symptoms of schizophrenia. Front Cell Neurosci (2013) 7:31. doi: $10.3389 /$ fncel.2013.00031
72. Gilmour G, Dix S, Fellini L, Gastambide F, Plath N, Steckler T, et al. NMDA receptors, cognition and schizophrenia - testing the validity of the NMDA receptor hypofunction hypothesis. Neuropharmacology (2012) 62:1401-12. doi:10.1016/j.neuropharm.2011.03.015

73. Javitt DC. Glutamate as a therapeutic target in psychiatric disorders. Mol Psychiatry (2004) 9:984-97, 979. doi:10.1038/sj.mp.4001602

74. Zhou Q, Sheng M. NMDA receptors in nervous system diseases. Neuropharmacology (2013) 74:69-75. doi:10.1016/j.neuropharm.2013.03.030

75. Theberge J, Bartha R, Drost DJ, Menon RS, Malla A, Takhar J, et al. Glutamate and glutamine measured with 4.0 T proton MRS in never-treated patients with schizophrenia and healthy volunteers. Am J Psychiatry (2002) 159:1944-6. doi:10.1176/appi.ajp.159.11.1944

76. Olbrich HM, Valerius G, Rusch N, Buchert M, Thiel T, Hennig J, et al. Frontolimbic glutamate alterations in first episode schizophrenia: evidence from a magnetic resonance spectroscopy study. World J Biol Psychiatry (2008) 9:59-63. doi:10.1080/15622970701227811

77. Ota M, Ishikawa M, Sato N, Hori H, Sasayama D, Hattori K, et al. Glutamatergic changes in the cerebral white matter associated with schizophrenic exacerbation. Acta Psychiatr Scand (2012) 126:72-8. doi:10.1111/j.1600-0447.2012. 01853.x

78. Schwartz TL, Sachdeva S, Stahl SM. Glutamate neurocircuitry: theoretical underpinnings in schizophrenia. Front Pharmacol (2012) 3:195. doi:10.3389/ fphar.2012.00195

79. Xiao L, Xu H, Zhang Y, Wei Z, He J, Jiang W, et al. Quetiapine facilitates oligodendrocyte development and prevents mice from myelin breakdown and behavioral changes. Mol Psychiatry (2008) 13:697-708. doi:10.1038/sj.mp. 4002064

80. Zhang Y, Xu H, Jiang W, Xiao L, Yan B, He J, et al. Quetiapine alleviates the cuprizone-induced white matter pathology in the brain of C57BL/6 mouse. Schizophr Res (2008) 106:182-91. doi:10.1016/j.schres.2008. 09.013

81. Garver DL, Holcomb JA, Christensen JD. Compromised myelin integrity during psychosis with repair during remission in drug-responding schizophrenia. Int J Neuropsychopharmacol (2008) 11:49-61. doi:10.1017/ S1461145707007730

82. Bartzokis G, Lu PH, Stewart SB, Oluwadara B, Lucas AJ, Pantages J, et al. In vivo evidence of differential impact of typical and atypical antipsychotics on intracortical myelin in adults with schizophrenia. Schizophr Res (2009) 113:322-31. doi:10.1016/j.schres.2009.06.014

83. Ferno J, Raeder MB, Vik-Mo AO, Skrede S, Glambek M, Tronstad KJ, et al. Antipsychotic drugs activate SREBP-regulated expression of lipid biosynthetic genes in cultured human glioma cells: a novel mechanism of action? Pharmacogenomics J (2005) 5:298-304. doi:10.1038/sj.tpj.6500323

84. Ferno J, Skrede S, Vik-Mo A, Havik B, Steen V. Drug-induced activation of SREBP-controlled lipogenic gene expression in CNS-related cell lines: marked differences between various antipsychotic drugs. BMC Neurosci (2006) 7:69. doi:10.1186/1471-2202-7-69

85. Skrede S, Fernø J, Vázquez MJ, Fjær S, Pavlin T, Lunder N, et al. Olanzapine, but not aripiprazole, weight-independently elevates serum triglycerides and activates lipogenic gene expression in female rats. Int J Neuropsychopharmacol (2012) 15:163-79. doi:10.1017/S1461145711001271

86. Leucht S, Cipriani A, Spineli L, Mavridis D, Örey D, Richter F, et al. Comparative efficacy and tolerability of 15 antipsychotic drugs in schizophrenia: a multiple-treatments meta-analysis. Lancet (2013) 382:951-62. doi:10.1016/ S0140-6736(13)60733-3

87. Procyshyn RM, Wasan KM, Thornton AE, Barr AM, Chen EY, Pomarol-Clotet E, et al. Changes in serum lipids, independent of weight, are associated with changes in symptoms during long-term clozapine treatment. J Psychiatry Neurosci (2007) 32:331-8.

88. Lally J, Gallagher A, Bainbridge E, Avalos G, Ahmed M, McDonald C. Increases in triglyceride levels are associated with clinical response to clozapine treatment. J Psychopharmacol (2013) 27:401-3. doi:10.1177/0269881112472568

89. Amminger GP, Schafer MR, Papageorgiou K, Klier CM, Cotton SM, Harrigan $\mathrm{SM}$, et al. Long-chain omega-3 fatty acids for indicated prevention of psychotic disorders: a randomized, placebo-controlled trial. Arch Gen Psychiatry (2010) 67:146-54. doi:10.1001/archgenpsychiatry.2009.192

90. Peters BD, Machielsen MW, Hoen WP, Caan MW, Malhotra AK, Szeszko PR, et al. Polyunsaturated fatty acid concentration predicts myelin integrity in 
early-phase psychosis. Schizophr Bull (2013) 39:830-8. doi:10.1093/schbul/ sbs089

91. Kaddurah-Daouk R, McEvoy J, Baillie RA, Lee D, Yao JK, Doraiswamy PM, et al. Metabolomic mapping of atypical antipsychotic effects in schizophrenia. Mol Psychiatry (2007) 12:934-45. doi:10.1038/sj.mp.4002000

92. Yao J, Keshavan M. Antioxidants, redox signaling, and pathophysiology in schizophrenia: an integrative view. Antioxid Redox Signal (2011) 15:2011-35. doi:10.1089/ars.2010.3603

93. Zhang XY, Chen DC, Xiu MH, Tang W, Zhang F, Liu L, et al. Plasma total antioxidant status and cognitive impairments in schizophrenia. Schizophr Res (2012) 139:66-72. doi:10.1016/j.schres.2012.04.009

94. Meyer U, Schwarz MJ, Muller N. Inflammatory processes in schizophrenia: a promising neuroimmunological target for the treatment of negative/cognitive symptoms and beyond. Pharmacol Ther (2011) 132:96-110. doi:10.1016/j.pharmthera.2011.06.003

95. Doorduin J, de Vries EF, Willemsen AT, de Groot JC, Dierckx RA, Klein HC. Neuroinflammation in schizophrenia-related psychosis: a PET study. J Nucl Med (2009) 50:1801-7. doi:10.2967/jnumed.109.066647

96. Ripke S, Sanders A, Kendler K, Levinson D, Sklar P, Holmans P, et al. Genomewide association study identifies five new schizophrenia loci. Nat Genet (2011) 43:969-76. doi:10.1038/ng.940

97. Debnath M, Cannon DM, Venkatasubramanian G. Variation in the major histocompatibility complex [MHC] gene family in schizophrenia: associations and functional implications. Prog Neuropsychopharmacol Biol Psychiatry (2013) 42:49-62. doi:10.1016/j.pnpbp.2012.07.009

98. Pickard B. Progress in defining the biological causes of schizophrenia. Expert Rev Mol Med (2011) 13:e25. doi:10.1017/S1462399411001955

99. Sequeira PA, Martin MV, Vawter MP. The first decade and beyond of transcriptional profiling in schizophrenia. Neurobiol Dis (2012) 45:23-36. doi:10.1016/ j.nbd.2011.03.001

100. Kayser M, Dalmau J. The emerging link between autoimmune disorders and neuropsychiatric disease. J Neuropsychiatry Clin Neurosci (2011) 23:90-97. doi:10.1176/appi.neuropsych.23.1.90

101. Dalmau J, Gleichman AJ, Hughes EG, Rossi JE, Peng X, Lai M, et al. AntiNMDA-receptor encephalitis: case series and analysis of the effects of antibodies. Lancet Neurol (2008) 7:1091-8. doi:10.1016/S1474-4422(08)70224-2

102. American College of Rheumatology. The American College of Rheumatology nomenclature and case definitions for neuropsychiatric lupus syndromes. Arthritis Rheum (1999) 42:599-608. doi:10.1002/1529-0131(199904) 42:4<599::AID-ANR2>3.0.CO;2-F

103. Noto C, Gadelha A, Belangero SI, Spindola LM, Rocha NP, de Miranda AS, et al. Circulating levels of sTNFR1 as a marker of severe clinical course in schizophrenia. J Psychiatr Res (2013) 47:467-71. doi:10.1016/j.jpsychires.2012.12.010

104. Dean B. Understanding the role of inflammatory-related pathways in the pathophysiology and treatment of psychiatric disorders: evidence from human peripheral studies and CNS studies. Int J Neuropsychopharmacol (2011) 14:997-1012. doi:10.1017/S1461145710001410

105. Meyer U. Anti-inflammatory signaling in schizophrenia. Brain Behav Immun (2011) 25:1507-18. doi:10.1016/j.bbi.2011.05.014

106. Miller B, Buckley P, Seabolt W, Mellor A, Kirkpatrick B. Meta-analysis of cytokine alterations in schizophrenia: clinical status and antipsychotic effects. Biol Psychiatry (2011) 70:663-671. doi:10.1016/j.biopsych.2011.04.013

107. Fineberg AM, Ellman LM. Inflammatory cytokines and neurological and neurocognitive alterations in the course of schizophrenia. Biol Psychiatry (2013) 73:951-66. doi:10.1016/j.biopsych.2013.01.001

108. Drexhage RC, Knijff EM, Padmos RC, Heul-Nieuwenhuijzen LV, Beumer W, Versnel MA, et al. The mononuclear phagocyte system and its cytokine inflammatory networks in schizophrenia and bipolar disorder. Expert Rev Neurother (2009) 10:59-76. doi:10.1586/ern.09.144

109. Hope S, Melle I, Aukrust P, Steen NE, Birkenaes AB, Lorentzen S, et al. Similar immune profile in bipolar disorder and schizophrenia: selective increase in soluble tumor necrosis factor receptor I and von Willebrand factor. Bipolar Disord (2009) 11:726-34. doi:10.1111/j.1399-5618.2009.00757.x

110. Potvin S, Stip E, Sepehry A, Gendron A, Bah R, Kouassi E. Inflammatory cytokine alterations in schizophrenia: a systematic quantitative review. Biol Psychiatry (2008) 63:801-808. doi:10.1016/j.biopsych.2007.09.024

111. Anthony DC, Pitossi FJ. Special issue commentary: the changing face of inflammation in the brain. Mol Cell Neurosci (2013) 53:1-5. doi:10.1016/j.mcn.2012. 11.005
112. Beumer W, Gibney SM, Drexhage RC, Pont-Lezica L, Doorduin J, Klein $\mathrm{HC}$, et al. The immune theory of psychiatric diseases: a key role for activated microglia and circulating monocytes. J Leukoc Biol (2012) 92:959-75. doi:10.1189/jlb.0212100

113. van Berckel BN, Bossong MG, Boellaard R, Kloet R, Schuitemaker A, Caspers E, et al. Microglia activation in recent-onset schizophrenia: a quantitative (R)[11C]PK11195 Positron Emission Tomography Study. Biol Psychiatry (2008) 64:820-2. doi:10.1016/j.biopsych.2008.04.025

114. Pasternak O, Sochen N, Gur Y, Intrator N, Assaf Y. Free water elimination and mapping from diffusion MRI. Magn Reson Med (2009) 62:717-30. doi:10.1002/mrm.22055

115. Pasternak O, Westin C, Bouix S, Seidman L, Goldstein J, Woo T, et al. Excessive extracellular volume reveals a neurodegenerative pattern in schizophrenia onset. J Neurosci (2012) 32(48):17365-72. doi:10.1523/JNEUROSCI.2904- 12. 2012

116. Steiner J, Bogerts B, Sarnyai Z, Walter M, Gos T, Bernstein H-G, et al. Bridging the gap between the immune and glutamate hypotheses of schizophrenia and major depression: potential role of glial NMDA receptor modulators and impaired blood-brain barrier integrity. World J Biol Psychiatry (2012) 13:482-92. doi:10.3109/15622975.2011.583941

117. Erhardt S, Blennow K, Nordin C, Skogh E, Lindström LH, Engberg G. Kynurenic acid levels are elevated in the cerebrospinal fluid of patients with schizophrenia. Neurosci Lett (2001) 313:96-8. doi:10.1016/S0304-3940(01) 02242-X

118. Schwarcz R, Rassoulpour A, Wu H-Q, Medoff D, Tamminga CA, Roberts RC. Increased cortical kynurenate content in schizophrenia. Biol Psychiatry (2001) 50:521-30. doi:10.1016/S0006-3223(01)01078-2

119. Schwarcz R, Bruno JP, Muchowski PJ, Wu H-Q. Kynurenines in the mammalian brain: when physiology meets pathology. Nat Rev Neurosci (2012) 13:465-77. doi:10.1038/nrn3257

120. Erhardt S, Schwieler L, Emanuelsson C, Geyer M. Endogenous kynurenic acid disrupts prepulse inhibition. Biol Psychiatry (2004) 56:255-60. doi:10.1016/j. biopsych.2004.06.006

121. Stone TW, Darlington LG. The kynurenine pathway as a therapeutic target in cognitive and neurodegenerative disorders. Br J Pharmacol (2013) 169:1211-27. doi:10.1111/bph.12230

122. Wonodi I, Schwarcz R. Cortical kynurenine pathway metabolism: a novel target for cognitive enhancement in schizophrenia. Schizophr Bull (2010) 36:211-8. doi:10.1093/schbul/sbq002

123. Baran H, Kepplinger B. Cerebrolysin lowers kynurenic acid formation - an in vitro study. Eur Neuropsychopharmacol (2009) 19:161-8. doi:10.1016/j. euroneuro.2008.09.003

124. Shifu X, Haibo X, Guanjun L, Chengmei Y, Xia L, Chao C, et al. Therapeutic effects of cerebrolysin added to risperidone in patients with schizophrenia dominated by negative symptoms. Aust N Z J Psychiatry (2012) 46:153-60. doi:10.1177/0004867411433213

125. Thome J, Doppler E. Safety profile of cerebrolysin: clinical experience from dementia and stroke trials. Drugs Today (2012) 48(Suppl A):63-9. doi:10.1358/ dot.2012.48(Suppl.A).1739724

126. Alvarez XA, Cacabelos R, Sampedro C, Aleixandre M, Linares C, Granizo E, et al. Efficacy and safety of cerebrolysin in moderate to moderately severe Alzheimer's disease: results of a randomized, double-blind, controlled trial investigating three dosages of cerebrolysin. Eur J Neurol (2011) 18:59-68. doi:10.1111/j.1468-1331.2010.03092.x

127. Plosker G, Gauthier S. Cerebrolysin. Drugs Aging (2009) 26:893-915. doi:10. 2165/11203320-000000000-00000

128. Chen C-C, Wei S-T, Tsaia S-C, Chen X-X, Cho D-Y. Cerebrolysin enhances cognitive recovery of mild traumatic brain injury patients: double-blind, placebocontrolled, randomized study. Br J Neurosurg (2013) 27:803-7. doi:10.3109/ 02688697.2013.793287

129. Baran H, Kepplinger B. d-Cycloserine lowers kynurenic acid formation new mechanism of action. Eur Neuropsychopharmacol (2013). doi:10.1016/j. euroneuro.2013.10.006

130. Goff DC. D-cycloserine: an evolving role in learning and neuroplasticity in schizophrenia. Schizophr Bull (2012) 38:936-41. doi:10.1093/schbul/sbs012

131. Fogal B, Hewett SJ. Interleukin-1 $\beta$ : a bridge between inflammation and excitotoxicity? J Neurochem (2008) 106:1-23. doi:10.1111/j.1471-4159.2008.05315.x

132. Gardoni F, Boraso M, Zianni E, Corsini E, Galli C, Cattabeni F, et al. Distribution of interleukin-1 receptor complex at the synaptic membrane driven by 
interleukin-1beta and NMDA stimulation. J Neuroinflammation (2011) 8:14. doi:10.1186/1742-2094-8-14

133. Chew LJ, Fusar-Poli P, Schmitz T. Oligodendroglial alterations and the role of microglia in white matter injury: relevance to schizophrenia. Dev Neurosci (2013) 35:102-29. doi:10.1159/000346157

134. Schmitz T, Chew L-J. Cytokines and myelination in the central nervous system. ScientificWorldJournal (2008) 8:1119-47. doi:10.1100/tsw.2008.140

135. Najjar S, Pearlman D, Alper K, Najjar A, Devinsky O. Neuroinflammation and psychiatric illness. J Neuroinflammation (2013) 1(10):43. doi:10.1186/17422094-10-43

136. Schroeter ML, Abdul-Khaliq H, Krebs M, Diefenbacher A, Blasig IE. Neuronspecific enolase is unaltered whereas S100B is elevated in serum of patients with schizophrenia - original research and meta-analysis. Psychiatry Res (2009) 167:66-72. doi:10.1016/j.psychres.2008.01.002

137. Kerschensteiner M, Stadelmann C, Dechant G, Wekerle H, Hohlfeld R. Neurotrophic cross-talk between the nervous and immune systems: implications for neurological diseases. Ann Neurol (2003) 53:292-304. doi:10.1002/ana. 10446

138. Nurjono M, Lee J, Chong SA. A review of brain-derived neurotrophic factor as a candidate biomarker in schizophrenia. Clin Psychopharmacol Neurosci (2012) 10:61-70. doi:10.9758/cpn.2012.10.2.61

139. Nieto R, Kukuljan M, Silva H. BDNF and schizophrenia: from neurodevelopment to neuronal plasticity, learning, and memory. Front Psychiatry (2013) 4:45. doi:10.3389/fpsyt.2013.00045

140. Goff DC. Future perspectives on the treatment of cognitive deficits and negative symptoms in schizophrenia. World Psychiatry (2013) 12:99-107. doi:10.1002/wps.20026

141. Monji A, Kato TA, Mizoguchi Y, Horikawa H, Seki Y, Kasai M, et al. Neuroinflammation in schizophrenia especially focused on the role of microglia. Prog Neuropsychopharmacol Biol Psychiatry (2013) 42:115-21. doi:10.1016/j.pnpbp. 2011.12.002

142. Ceresoli-Borroni G, Rassoulpour A, Wu HQ, Guidetti P, Schwarcz R. Chronic neuroleptic treatment reduces endogenous kynurenic acid levels in rat brain. J Neural Transm (2006) 113:1355-65. doi:10.1007/s00702-005-0432-z

143. Nitta M, Kishimoto T, Müller N, Weiser M, Davidson M, Kane JM, et al. Adjunctive use of nonsteroidal anti-inflammatory drugs for schizophrenia: a metaanalytic investigation of randomized controlled trials. Schizophr Bull (2013) 39(6):1230-41. doi:10.1093/schbul/sbt070

144. Sommer IE, van Westrhenen R, Begemann MJ, de Witte LD, Leucht S, Kahn RS. Efficacy of anti-inflammatory agents to improve symptoms in patients with schizophrenia: an update. Schizophr Bull (2013) 40(1):181-91. doi:10.1093/schbul/sbt139

145. Muller N, Riedel M, Schwarz MJ, Engel RR. Clinical effects of COX-2 inhibitors on cognition in schizophrenia. Eur Arch Psychiatry Clin Neurosci (2005) 255:149-51. doi:10.1007/s00406-004-0548-4

146. Sirén A-L, Faßhauer T, Bartels C, Ehrenreich H. Therapeutic potential of erythropoietin and its structural or functional variants in the nervous system. Neurotherapeutics (2009) 6:108-27. doi:10.1016/j.nurt.2008.10.041

147. Ehrenreich H, Hinze-Selch D, Stawicki S, Aust C, Knolle-Veentjer S, Wilms S, et al. Improvement of cognitive functions in chronic schizophrenic patients by recombinant human erythropoietin. Mol Psychiatry (2007) 12:206-20. doi:10.1038/si.mp.4001907

148. Wustenberg T, Begemann M, Bartels C, Gefeller O, Stawicki S, Hinze-Selch D, et al. Recombinant human erythropoietin delays loss of gray matter in chronic schizophrenia. Mol Psychiatry (2011) 16:26-36. doi:10.1038/mp.2010.51

149. Fond G, Macgregor A, Attal J, Larue A, Brittner M, Ducasse D, et al. Treating patients with schizophrenia deficit with erythropoietin? Psychiatry Clin Neurosci (2012) 66:375-82. doi:10.1111/j.1440-1819.2012.02359.x

150. Jang W, Park J, Shin KJ, Kim J-S, Kim JS, Youn J, et al. Safety and efficacy of recombinant human erythropoietin treatment of non-motor symptoms in Parkinson's disease. J Neurol Sci (2013). doi:10.1016/j.jns.2013.11.015

151. Sargin D, Friedrichs H, El-Kordi A, Ehrenreich H. Erythropoietin as neuroprotective and neuroregenerative treatment strategy: comprehensive overview of 12 years of preclinical and clinical research. Best Pract Res Clin Anaesthesiol (2010) 24:573-94. doi:10.1016/j.bpa.2010.10.005

152. Domercq M, Matute C. Neuroprotection by tetracyclines. Trends Pharmacol Sci (2004) 25:609-12. doi:10.1016/j.tips.2004.10.001

153. Levkovitz Y, Mendlovich S, Riwkes S, Braw Y, Levkovitch-Verbin H, Gal G, et al. A double-blind, randomized study of minocycline for the treatment of negative and cognitive symptoms in early-phase schizophrenia. J Clin Psychiatry (2010) 71:138-149. doi:10.4088/JCP.08m04666yel

154. Chaudhry IB, Hallak J, Husain N, Minhas F, Stirling J, Richardson P, et al. Minocycline benefits negative symptoms in early schizophrenia: a randomised double-blind placebo-controlled clinical trial in patients on standard treatment. J Psychopharmacol (2012) 26:1185-93. doi:10.1177/0269881112444941

155. Kay SR, Fiszbein A, Opler LA. The Positive and Negative Syndrome Scale (PANSS) for schizophrenia. Schizophr Bull (1987) 13:261-76. doi:10.1093/ schbul/13.2.261

156. Overall J, Gorham D. The Brief Psychiatric Rating Scale. Psychol Rep (1962) 10:799-812. doi:10.2466/pr0.1962.10.3.799

Conflict of Interest Statement: The authors declare that the research was conducted in the absence of any commercial or financial relationships that could be construed as a potential conflict of interest.

Received: 01 October 2013; accepted: 20 January 2014; published online: 04 February 2014.

Citation: Kroken RA, Løberg E-M, Drønen T, Grüner R, Hugdahl K, Kompus K, Skrede $S$ and Johnsen E (2014) A critical review of pro-cognitive drug targets in psychosis: convergence on myelination and inflammation. Front. Psychiatry 5:11. doi: 10.3389/fpsyt.2014.00011

This article was submitted to Schizophrenia, a section of the journal Frontiers in Psychiatry.

Copyright $\odot 2014$ Kroken, Løberg, Drønen, Grüner, Hugdahl, Kompus, Skrede and Johnsen. This is an open-access article distributed under the terms of the Creative Commons Attribution License (CC BY). The use, distribution or reproduction in other forums is permitted, provided the original author(s) or licensor are credited and that the original publication in this journal is cited, in accordance with accepted academic practice. No use, distribution or reproduction is permitted which does not comply with these terms 